\title{
BEHAVIORAL SCIENCE AND ORIENTAL ETHOLOGY
}

\author{
Koji SATO \\ Kyoto University
}

Just after the War (1947) Kurt Lewin wrote in the beginning of his last paper "Frontiers in group dynamics" that "One of the by-products of the second World War of which society is hardly aware is the new stage of development which the social sciences have reached. This development indeed may prove to be as revolutionary as the atom bomb. .... The scientific aspects of this development center around three objectives: 1. Integrating social sciences. 2. Moving from the description of social bodies to dynamic problems of changing group life. 3. Developing new instruments and techniques of social research." Group dynamics was such a new discipline. But recently the term "behavioral science" has become a key word for the activities of psychologists or other scientists in the neighboring fields. The word was invented by J. G. Miller's group who were working in Chicago around 1949. It is broader than social science and integrates biological sciences. It may be characterized as the interdisciplinary study of man, aiming at a unified theory of human behavior, covering very broad fields from pharmacology to political ro economical sciences. The writer is interested to see the American behavioral science in relationship to European ethology. N. Tinbergen compared the modern European ethology with the American behaviorism, but this refers to animals, rather than to men. The ethology, however, has another meaning in J.S. Mill's usage, which was also discussed by Allport in his "Personality: a psychological interpretation (1937)." It is the science of formation of national or collective character as well as individual. It is the science which corresponds to the act of education in the widest sense of the term. Then this ethology cames near to modern behavioral science. Behavioral science aims to be the objective study of behavior while Mill's ethology is the Exact Science of Human Nature. In their actual forms, the ethology in the Nineteenth Century is of course different, but their emphasis is quite similar. The writer wishes to call attention to their relationship to the Oriental wisdom on human nature, which covers medicine, psychology, philosophy, religion and arts (fine arts as well as chivalry arts). These Oriental teachings are so closely interrelated, and the central problem is the personality training with mental and bodily adjustment of the person. The writer wishes to suggest a number of concrete problems to investigate:

Personality theories of the East and the West.

Oriental medicine and psychosomatic medicine.

Creativity and Zen.

Oriental arts and modern arts.

Psychotherapy in the West and the Oriental wisdom on human nature.

Dynamics of ' $k i$ ' (psychovitality) in individuals and groups.

Personality training in Western sports and Japanese chivalry arts.

Oriental varieties of religious experience.

Man-machine-system design and Oriental ethology.

Oriental views on human nature and ways toward world peace. 